\title{
System Simulation and Policy Response: Long-Term Care Needs of the Elderly with Disabilities in China (2021-2050)
}

\author{
Qiyini Ma, Hong Mi* \\ School of Public Affairs, Zhejiang University, Hangzhou, China \\ Email: *spsswork@zju.edu.cn
}

How to cite this paper: Ma, Q. Y. N., \& Mi, H. (2021). System Simulation and Policy Response: Long-Term Care Needs of the Elderly with Disabilities in China (2021-2050). Open Journal of Social Sciences, 9, 553-561. https://doi.org/10.4236/jss.2021.95030

Received: April 19, 2021

Accepted: May 22, 2021

Published: May 25, 2021

\begin{abstract}
Background: In the near future, pressures on long-term care (LTC) are expected to grow with demographic transition. Higher demand for formal services is emerging in China also because of people's expectations for high-quality care. This study aims to provide quantitative estimates of the associated LTC financial liability in the medium to long run to 2050, and is expected to further facilitate policy design on national LTC systems, which begin to be formulated and debated. Methods: We first analyze the health status of Chinese elderly through the Sample Survey of the Aged Population in Urban and Rural China (SSAPUR) in 2015, 2016 and 2017, the largest database of research on aging in China. Subsequently, we estimate LTC needs and the government's financial burden for the next 3 decades according Qingdao model. Results: The average elderly disability rate is $4.4 \%$ in $2015-2017$, and the gender differences (3.9\% for males, $4.67 \%$ for females), disparities between rural and urban areas, age differences exist. The proportion of public expenditure on long-term care costs will increase from 0.35 percent in 2021 to 0.68 percent in 2050, and that of proportion in GDP will increase from 0.1 percent to 0.2 percent. Conclusions: Compared with OECD countries, China's LTC system started late and developed relatively slowly. The "policy window" between 2021 and 2036 is critical for China in developing LTC policies. In the period of "gradually getting wealthy and quickly getting old", policy-makers should give priority to achieve "healthy aging" instead of "survival aging".
\end{abstract}

\section{Keywords}

Long-Term Care, Elderly Disability, SSAPUR, Forecasting Cost, Policy Design 


\section{Introduction}

The demographic structure of China is expected to change rapidly in the near future. Aging populations pose serious challenges for the health and long-term care systems around the world (Kinsella \& He, 2009). However, the challenges are particularly acute in China, where demographic shifts are rapid, exacerbated by the one-child family policy (Hesketh et al., 2005). Accordingly, the demand for long-term care services and its cost for the elderly are growing rapidly, catalyzed by government policies and private-sector initiatives (Xu et al., 2019; Zeng et al., 2019; Feng et al., 2012). Advocates for the elderly, policymakers, and health care providers share a growing perception that the scope of services currently available to the elderly is inadequate.

Long-term care aims to relieve family care burden, which is one of the key measures to improve the survival quality of the elderly with disabilities. But, long-term care is often unaffordable in the absence of social protection. For this reason, countries have started exploring long-term care insurance (LTCI) systems. Accurate measurement of elderly disability and long-term care costs have gradually become important basis for formulating long-term care policies (Zeng et al., 2020). Countries use different approaches to assess eligibility for long-term care supports. However, there is not a universally accepted international measure of long-term care needs, and the systems vary in both the scoring systems that states use to rate severity of need and in how these scores are applied in practice (Muir, 2017). In China, there is even no national model for long-term care needs assessment, and in the LTCI pilot cities, local authorities rely on their own practice experience.

An aging population and increased longevity mean that long term care will become progressively more expensive. As "steadily promote the establishment of a long-term care insurance system", outlined in the 14th Five-Year Plan for National Economic and Social Development and the Long-Range Objectives through the Year 2035, has become the focus of Chinese government and academic circles, this review aims to examine the health status of Chinese elderly, and through the population projections to estimate long-term care costs, with a hope to provide policy recommendations for the construction of China's national long-term care system.

\section{Data and Method}

The data used in this paper are from the fourth wave (2015-2017) of the sample survey on the living conditions of the elderly in urban and rural China, which is a special national survey on the elderly population. The Sample Survey of the Aged Population in Urban and Rural China (SSAPUR) is conducted by Chinese National Committee on Ageing. It is a follow-up investigation with large scale of samples, covering all provinces of China. The survey content includes population, economy, health, services, social participation, spiritual culture, rights protection, livable environment and many other aspects. The survey adopts mul- 
ti-level sampling and tracking survey methods, selecting Chinese citizens aged over 60 years as the survey subjects. Through the means of household interviews and questionnaire surveys, a large variety of data has been collected. In China, SSAPUR is by far the largest database of elderly people.

This paper uses the data of the $4^{\text {th }}$ SSAPUR, which was organized in 2015-2017. The $4^{\text {th }}$ SSAPUR for the first time to achieve the nationwide survey goal, covered all provinces, autonomous regions, municipalities and Xinjiang Production and Construction Corps across the country, involving 466 counties (districts) and 1864 townships (sub-districts), 7456 village (residential) committees. The $4^{\text {th }}$ SSAPUR is a follow-up survey lasted for three years, obtaining data for the three years of 2015, 2016, and 2017. The sample size of the survey was 223,680 , and the sampling ratio was about $1 \%$. After data cleaning, 224,142 valid samples were collected in 2015, and 22,973 were collected in 2016. In addition to death and other causes, 22,340 were collected in 2017.

The performance of Activities of daily living (ADLs) is commonly used as objective indicators to assess elderly health. ADLs are routine activities people do every day without assistance. It is important in determining what type of long-term care and health coverage a person will need as they age. There are six basic ADLs: eating, bathing, getting dressed, toileting, mobility, and continence. In the SSAPUR questionnaire, the respondent is asked to indicate how much "difficulty" he or she experiences ("easy to do", "difficult to do" or "cannot do it") in the normal performance of the given activities.

In our study, we take ADLs as the disability criterion, the health status of the elderly (60 years old and above) is divided into two categories: the inability to do at least one $\mathrm{ADL}$ is regarded as disabled group; the rest of the samples are regarded as self-care group. In our study, disability rate is equal to the number of disabled people divided by the total number of elderly population (aged over 60 years).

\section{Evaluation of the Health Status of the Elderly in China}

In general, the elderly has a strong ability to take care of themselves in China. From 2015 to 2017, more than 95 percent of the elderly have the ability to do self-care (see Table 1). However, the number seems to be tapering off during this period. Whereas, the result shows that from 2015 to 2017, the disability incidence of the elderly experiences a slight upward trend, from 4.01 percent in 2015 to 4.63 percent in 2017.

Bridging the urban-rural gap in China is a historic task. But overall, the situation of the gap between urban and rural areas has not fundamentally changed. Regional disparities in health also emerge. The disability rate of the elderly in rural areas increased rapidly, and that of the elderly in urban areas tends to be stable. Compared with urban areas, the disability rate in rural areas increases from 3.9 percent to 4.8 percent, with a larger increase of 0.9 percent. The rate of the disabled elderly in urban areas rises from 4.1 percent to 4.7 percent, with a slight increase of 0.6 percent. Along with the development of urbanization, the 
Table 1. Elderly health status by resident, gender and age in China, 2015-2017, \%.

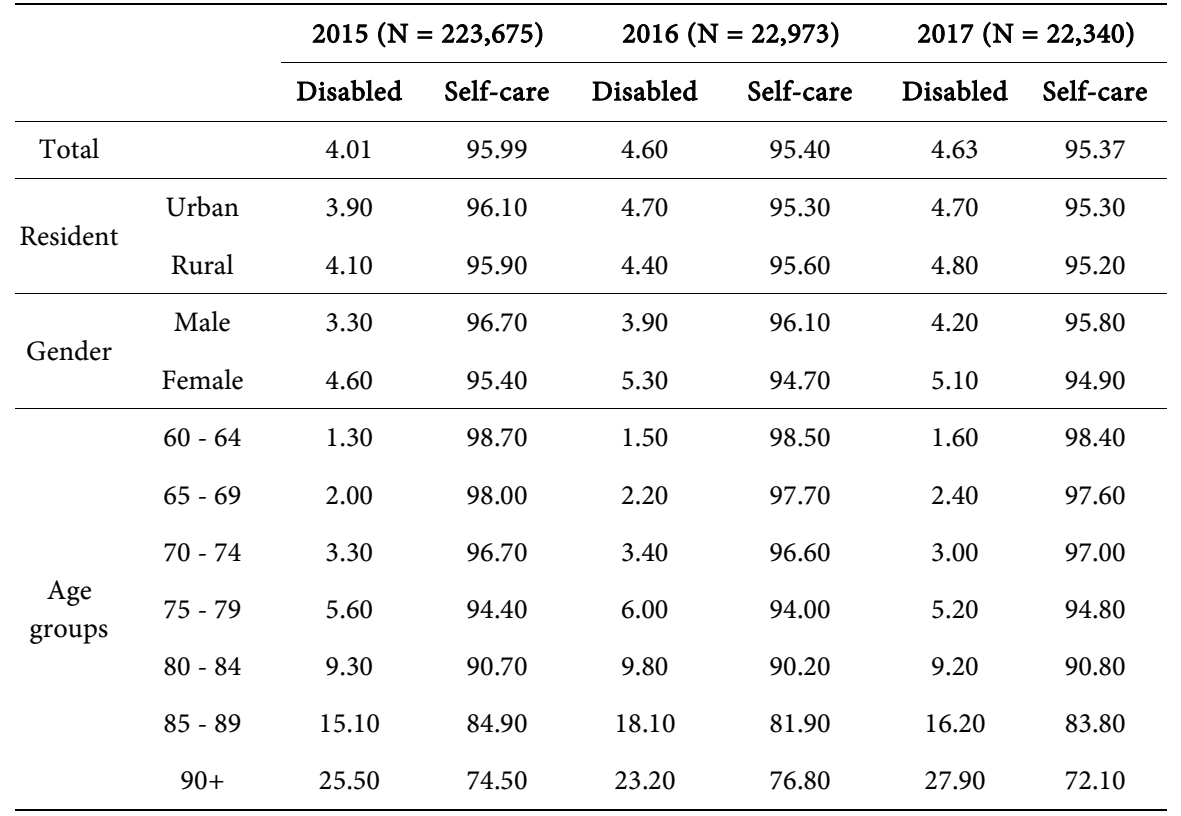

incidence of disability tends to be almost same between urban and rural areas in 2017. According to the present development trend, disability rates would be slightly higher in rural areas than in urban areas.

In regards to gender differences, the disability rate of female elderly is significantly higher than that of male, which is respectively 4.6 percent, 5.3 percent and 5.1 percent from 2015 to 2017 . The rate of disability in female elderly is more than 1 percent higher than that in male elderly. Aging is inevitably accompanied by the weakness of body's functions, and the characteristics of unhealthy longevity are obvious in women. Elderly women often live with diseases, and their years of living with diseases are higher than that of men. Due to medical advances, it seems that the disability gap between male and female has shrunk: in 2015 and 2016, the gap is 1.3 percent and 1.4 percent, but in 2017, it has narrowed to 0.9 percent.

People older than 65 years of age, especially those aged over 80 years, have the highest probability of receiving LTC services, while women are the main recipients of services (Colombo et al., 2011). It is clear that the older you get, the more likely you are to become disabled. We find that there seems to be a high probability of disability at a high speed after 80 years old, where it is called old-old. Disability varies between young-old and old-old. With the growth of age, the self-care ability of the elderly is constantly declining. The incidence of disability is close to 10 percent after people entering their eighties.

\section{Policy Simulation of the Population Size and the Cost of the Long-Term Care for Disabled Elderly in China (2021-2050)}

In this study, we take the geometric average of the three-year elderly disability 
rate in $2015-2017$ as the disability rate in $2021-2050$ (3.9\% for males, $4.67 \%$ for females), and we assume that the disability rate in China remains the same in the following years. According to results, the line chart of the total disabled elderly shows a sharp increase in the population size from 2021 to 2050 , spiking to 21,083 thousand people in 2050 (see Figure 1). The number of disabled elderly people has levelled off after a period of unusually rapid growth in 2021-2036. After 2036, the number continues to grow at a relatively steady rate.

According to the practical experience of long-term care insurance pilot scheme in Qingdao, the annual long-term care insurance expenditure is 350 million yuan, covering a total of 50,000 disabled elderly people, with an average annual long-term care expenditure of 7000 yuan per person in 2018 . We suppose that the growth rate of LTC costs is consistent with the annual growth rate of GDP. If the elderly disability rate remains unchanged until 2050 (3.9\% for males, $4.67 \%$ for females), the total cost of long-term care for disabled elderly by 2050 will reach 671 billion yuan (see Table 2).

We assume that the growth rate of fiscal expenditure increases at the same rate as GDP. According to our calculations, the proportion of fiscal expenditure on long-term care costs will increase from 0.35 percent in 2021 to 0.68 percent in 2050 , and that of proportion in GDP will increase from 0.1 percent to 0.2 percent (see Table 3 ).

In developed countries, long-term care systems have made great progress since the 1960s (Zeng et al., 2019). In the long history, OECD countries have built long-term care systems with their own characteristics according to social and economic conditions. Through continuous development and reforms, the long-term care systems are much more mature than China. If the Qingdao model is implemented nationwide, China's expenditure on long-term care (less than 0.3 percent of GDP) by 2050, will still be lower than the average of OECD countries (1.3 percent of GDP in 2020) (Figure 2). China still has a long way to go in response to the positive response to an aging population.

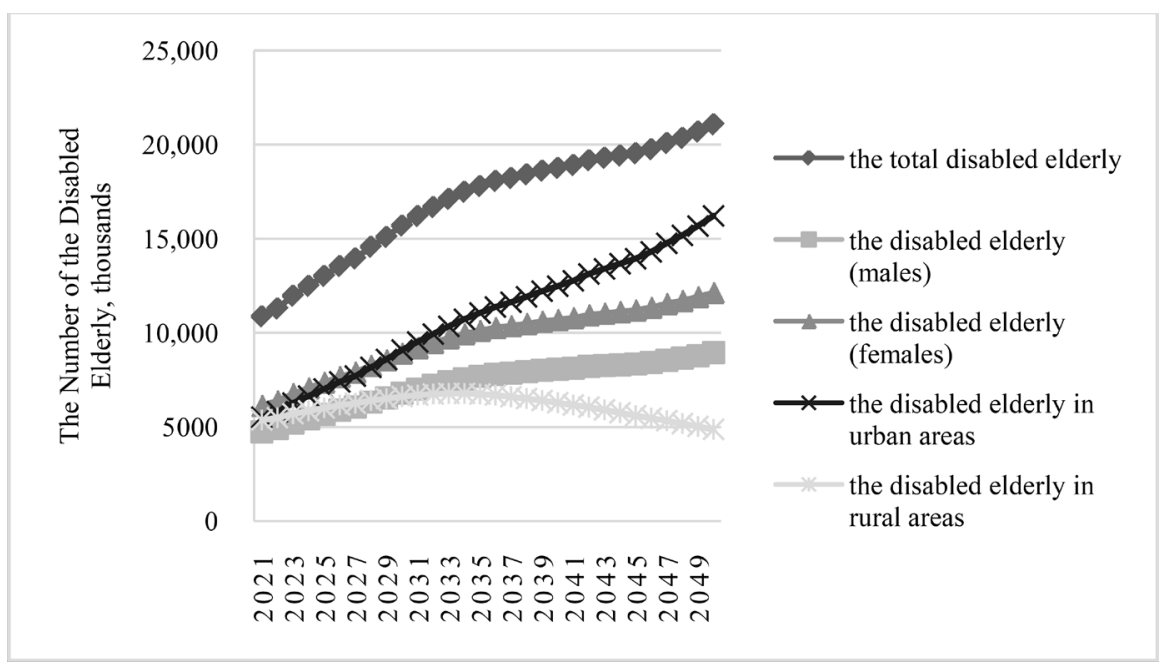

Figure 1. The population projection of disabled elderly in China, 2021-2050, thousands. 
Table 2. The projected cost of long-term care for the elderly with disabilities, 2021-2050.

\begin{tabular}{|c|c|c|c|c|c|c|c|}
\hline Year & $\begin{array}{l}\text { The growth } \\
\text { of LTC costs } \\
\text { (\%) }\end{array}$ & $\begin{array}{l}\text { Cost of LTC per } \\
\text { capita } \\
\text { (yuan per year) }\end{array}$ & $\begin{array}{l}\text { Total cost of } \\
\text { LTC (billion } \\
\text { yuan per year) }\end{array}$ & Year & $\begin{array}{c}\text { The growth } \\
\text { of LTC } \\
\text { costs (\%) }\end{array}$ & $\begin{array}{l}\text { Cost of LTC per } \\
\text { capita } \\
\text { (yuan per year) }\end{array}$ & $\begin{array}{l}\text { Total cost of } \\
\text { LTC (billion } \\
\text { yuan per year) }\end{array}$ \\
\hline 2021 & 6.32 & 8447 & 92 & 2036 & 4.51 & 18,161 & 328 \\
\hline 2022 & 6.15 & 8967 & 101 & 2037 & 4.44 & 18,967 & 346 \\
\hline 2023 & 6.00 & 9504 & 114 & 2038 & 4.37 & 19,795 & 365 \\
\hline 2024 & 5.85 & 10,060 & 126 & 2039 & 4.30 & 20,647 & 384 \\
\hline 2025 & 5.68 & 10,631 & 139 & 2040 & 4.24 & 21,522 & 404 \\
\hline 2026 & 5.56 & 11,222 & 152 & 2041 & 4.18 & 22,423 & 424 \\
\hline 2027 & 5.42 & 11,831 & 165 & 2042 & 4.13 & 23,349 & 448 \\
\hline 2028 & 5.30 & 12,457 & 182 & 2043 & 4.08 & 24,301 & 469 \\
\hline 2029 & 5.18 & 13,102 & 198 & 2044 & 4.03 & 25,282 & 491 \\
\hline 2030 & 5.07 & 13,766 & 216 & 2045 & 3.99 & 26,291 & 514 \\
\hline 2031 & 4.96 & 14,449 & 234 & 2046 & 3.95 & 27,329 & 540 \\
\hline 2032 & 4.86 & 15,151 & 253 & 2047 & 3.91 & 28,399 & 571 \\
\hline 2033 & 4.76 & 15,873 & 272 & 2048 & 3.88 & 29,500 & 601 \\
\hline 2034 & 4.67 & 16,615 & 291 & 2049 & 3.85 & 30,635 & 634 \\
\hline 2035 & 4.59 & 17,377 & 309 & 2050 & 3.82 & 31,805 & 671 \\
\hline
\end{tabular}

Table 3. Long-term care (LTC) costs as a percentage of GDP and fiscal expenditure, 2021-2050, \%.

\begin{tabular}{cccccc}
\hline Year & $\begin{array}{c}\text { LTC costs as a } \\
\text { percentage of GDP } \\
(\%)\end{array}$ & $\begin{array}{c}\text { LTC costs as a } \\
\text { percentage of fiscal } \\
\text { expenditure (\%) }\end{array}$ & Year & $\begin{array}{c}\text { LTC costs as a } \\
\text { percentage of GDP } \\
(\%)\end{array}$ & $\begin{array}{c}\text { LTC costs as a } \\
\text { percentage of fiscal } \\
\text { expenditure (\%) }\end{array}$ \\
\hline 2021 & 0.35 & 0.10 & 2036 & 0.58 & 0.17 \\
2022 & 0.36 & 0.11 & 2037 & 0.59 & 0.17 \\
2023 & 0.39 & 0.11 & 2038 & 0.59 & 0.18 \\
2024 & 0.40 & 0.12 & 2039 & 0.60 & 0.18 \\
2025 & 0.42 & 0.12 & 2040 & 0.61 & 0.18 \\
2026 & 0.44 & 0.13 & 2041 & 0.61 & 0.18 \\
2027 & 0.45 & 0.13 & 2042 & 0.62 & 0.18 \\
2028 & 0.47 & 0.14 & 2043 & 0.62 & 0.18 \\
2029 & 0.49 & 0.14 & 2044 & 0.63 & 0.19 \\
2030 & 0.51 & 0.15 & 2045 & 0.63 & 0.19 \\
2031 & 0.52 & 0.15 & 2046 & 0.64 & 0.19 \\
2032 & 0.54 & 0.16 & 2047 & 0.65 & 0.19 \\
2033 & 0.55 & 0.16 & 2048 & 0.66 & 0.19 \\
2034 & 0.56 & 0.17 & 2049 & 0.67 & 0.20 \\
2035 & 0.57 & 0.17 & 2050 & 0.68 & 0.19 \\
\hline
\end{tabular}




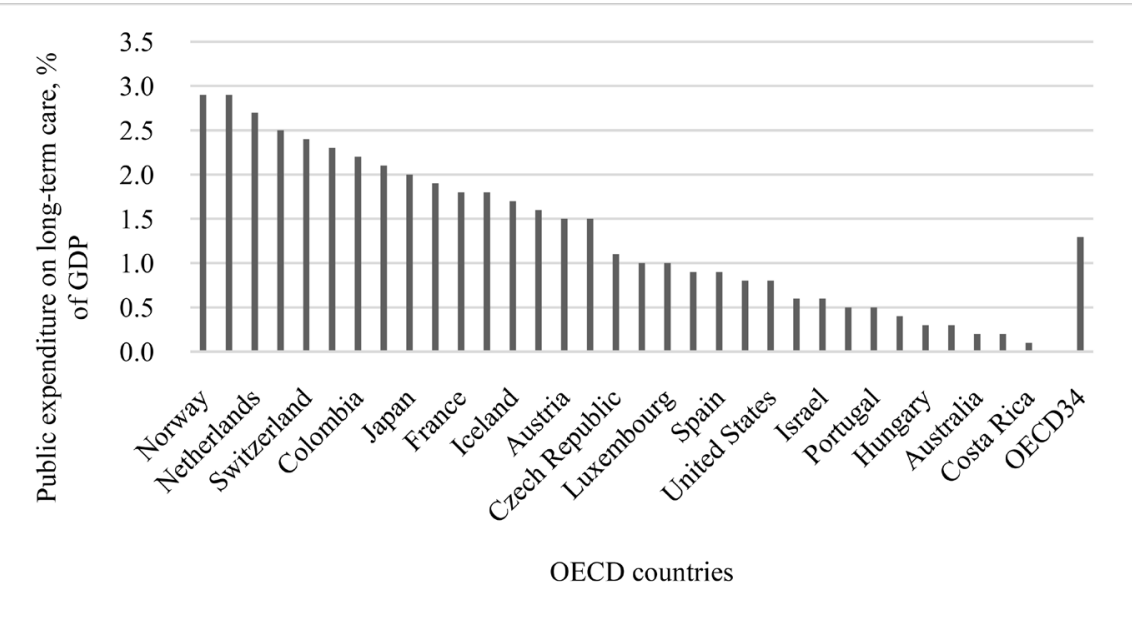

Source: OECD (2020), "Health expenditure and financing: Health expenditure indicators", OECD Health Statistics (database), https://doi.org/10.1787/data-00349-en (accessed on 17 April 2021). Notes: Last updated in November 2020. Data for Austria refers to 2018; Colombia, Japan and Australia refer to 2017; Israel refers to 2016.

Figure 2. Public expenditure on long-term care (health) as a share of GDP.

\section{Conclusion and Suggestions}

Four key messages can be drawn from this simulation exercise. First, our finding in this study highlight that the period between 2021 and 2036 is critical to establish a national long-term care system in China. Along with the rapid growth in the number of disabled elderly population, it is necessary to accelerate the construction of long-term care system nationwide before entering the peak period for aging. Second, the disparities between urban and rural China clearly indicate that the urban areas would be the worst hit of long-term care needs, as the number of disabled older persons is expected to be three times as many as in rural areas by 2050. Therefore, it is necessary to make LTC system effective in allocating resources between urban and rural areas. Third, gender-differentiated care services should be encouraged under the "Active Ageing Framework" to meet the swelling long-term care needs of female elderly. Fourth, based on "government responsibility for limited finance" theory, the paper suggests the innovation of the financing pattern to cope with the huge and rigid demand for long-term care services in the future. The financing responsibilities of the government, enterprises, individuals and society should be clarified.

China is continuing to work on long-term care system reforms and priorities for future work include increasing the number of LTCI pilot cities and establishing a relatively independent long-term care system nationwide as one of the social security systems. As of 2020, the long-term care pilot cities have been expanded to 49 cities, on the basis of 15 cities in the early stage (since 2016). However, the pilot time should not take too much time. Although conducting the pilots would help the government accumulate experience and make better policies, promoting long-term care insurance nationwide as soon as possible would help to improve policy efficiency so that the elderly could benefit from it. Besides, the 
long trial period will strengthen the particularity and difference of the system in the pilot area, making it difficult to realize a nationwide system with universal characteristics.

Based on the analysis presented, we suggest to seize the "policy window" (2021-2036) to establish LTC system as soon as possible in China, which includes a consistent national approach to assessing disability and care service quality. These are huge obstacles to institutional building at present. Personal experience with disability is an important aspect of any assessment of disability and hence assessments of it should combine objective observations with subjective self-report data. Therefore, it is necessary to further the hybrid assessment measures in the future, which helps to meet the needs of different target groups and thus better provide diversified care services to realize "healthy aging" instead of "survival aging".

\section{Acknowledgements}

The study is funded by Major Program of China Ministry of Education, "Theory, Method Innovation of Long-term Care Policy and Pilot Evaluation: International Experience and Development in China" (Grant No. 19JHQ014), Major Program of National Social Science Foundation of China, "Research on Multi-level and Multi-pillar Old-Age Insurance System" (Grant No. 21ZDA101), and Major Program of Zhejiang Provincial Social Science Foundation of China, "The Multi-state Prediction of Population Aging and the Simulation of Pension Policy in China (2018-2070)" (Grant No. 19YSXK03ZD).

\section{Conflicts of Interest}

The authors declare no conflicts of interest regarding the publication of this paper.

\section{References}

Colombo, F. et al. (2011). Help Wanted?: Providing and Paying for Long-Term Care, OECD Health Policy Studies. Paris: OECD Publishing. https://doi.org/10.1787/9789264097759-en

Feng, Z., Liu, C., Guan, X., \& Mor, V. (2012). China’s Rapidly Aging Population Creates Policy Challenges in Shaping a Viable Long-Term Care System. Health Affairs, 31, 2764-2773. https://doi.org/10.1377/hlthaff.2012.0535

Hesketh, T., Lu, L., \& Xing, Z. W. (2005). The Effect of China's One-Child Family Policy after 25 Years. The New England Journal of Medicine, 353, 1171-1176. http://dx.doi.org/10.1056/NEJMhpr051833

Kinsella, K., \& He, W. (2009). An Aging World: 2008. Washington DC: Census Bureau.

Muir, T. (2017). Measuring Social Protection for Long-Term Care, OECD Health Working Papers, No. 93. Paris: OECD Publishing. http://dx.doi.org/10.1787/a411500a-en

OECD (2020). Health Expenditure and Financing: Health Expenditure Indicators. OECD Health Statistics (Database), https://doi.org/10.1787/data-00349-en

Xu, X., Huang, X., Zhang, X., \& Chen, L. (2019), Family Economic Burden of Elderly 
Chronic Diseases: Evidence from China. Healthcare, 7, 99.

https://doi.org/10.3390/healthcare7030099

Zeng, L., Xu, X., Zhang, C., \& Chen, L. (2019). Factors Influencing Long-Term Care Service Needs among the Elderly Based on the Latest Anderson Model: A Case Study from the Middle and Upper Reaches of the Yangtze River. Healthcare, 7, 157.

https://doi.org/10.3390/healthcare7040157

Zeng, Q., Wang, Q., Zhang, L., \& Xu, X. (2020). Comparison of the Measurement of Long-Term Care Costs between China and Other Countries: A Systematic Review of the Last Decade. Healthcare, 8, 117. https://doi.org/10.3390/healthcare8020117 